\title{
HISTÓRIA DO PENSAMENTO GEOGRÁFICO
}

Katia Kayahara Silva, Edilaine Tiraboschi de Oliveira Bertucchi

Universidade do Oeste Paulista - UNOESTE. Curso de Pós Graduação em Gestão Escolar. E-mail: katiakayahara@yahoo.com.br

\section{RESUMO}

Este trabalho apresenta um breve relato sobre a história do pensamento geográfico, a partir da obra e história de alguns dos principais pensadores desta ciência, com o intuito de mostrar o percurso da geografia ao longo do tempo, através das transformações e colaborações que cada um dos autores citados acrescentou.

Palavras-chave: Geografia, Geógrafos, Escolas do Pensamento Geográfico, Matrizes do Pensamento Geográfico, Ciência.

\section{HISTORY OF GEOGRAPHICAL THOUGHT}

\section{ABSTRACT}

This paper presents a brief account of the history of geographical thought, from the work and history of some of the leading thinkers of this science, in order to show the route of geography over time, through the transformations and collaborations that each cited authors added.

Keywords: Geography, Geographers, Geographic Schools of Thought, Geographical Thought Headquarters, Science. 


\section{INTRODUÇÃO}

A geografia, como todas as ciências, está inserida dentro de um contexto social e sofre influencia do mesmo e, assim como a sociedade muda ao longo do tempo a ciência também se altera.

A geografia é um saber antigo, mas foi sistematizado enquanto ciência de forma tardia, entre o final do século XVII e o início do século XIX, na Alemanha. No Brasil os primeiros cursos universitários foram fundados no início do século $X X$, sob forte influencia de pesquisadores franceses.

Moreira, 2010, afirma que a história do pensamento geográfico é a historias dos geógrafos, por este motivo este trabalho apresenta a contribuição e importância de alguns pensadores que tiveram papel importante para a história do pensamento geográfico, obviamente, devido ao caráter deste trabalho, alguns pensadores importante não foram citados.

\section{OBJETIVOS}

- Compreender o a história do pensamento geográfico;

- Entender o desenvolvimento da geografia enquanto ciência;

- Analisar os as matizes do pensamento geográfico;

\section{MÉTODOS}

Este trabalho de pesquisa trata de uma abordagem qualitativa. Será feito um levantamento bibliográfico a cerca do tema, focando as obras do geógrafo Rui Moreira, com ênfase nos livros "O que é Geografia" e "O Pensamento Geográfico Brasileiro: as matrizes clássicas originárias", a primeira obra é um pequeno livro que trata de forma bem resumida a história do pensamento geográfico a partir da perspectiva das "escolas do pensamento geográfico", está visão a cerca da história do pensamento geográfico será questionada em "O Pensamento Geográfico Brasileiro: as matrizes clássicas originárias".

\section{DISCUSSÃO}

\section{As origens da geografia (Estrabão e Kant)}

Moreira (2009) considera Estrabão (64 a.c.-24 d.c.) o criador da geografia, este pensador assim definia esta ciência:

"a geografia familiariza-nos com os ocupantes da terra e dos oceanos, com a vegetação, os frutos e as peculiaridades dos vários quadrantes da terra; e o 
homem que a cultiva é um homem profundamente interessado no grande problema da vida e da felicidade" (MOREIRA, 2009, 8p.).

Porém, a geografia moderna surge com a revolução burguesa pelas mãos de Kant, filósofo Iluminista, que se preocupava com a defasagem da filosofia em relação à ciência do século XVIII (MOREIRA, 2010). Para Kant o conhecimento era dado pelas sensações corporais, inicialmente, sendo a percepção interna reveladora do homem e a percepção externa reveladora do homem, assim o espaço era considerado um dado a priori (MOREIRA, 2009). Cabia "a geografia a descrição do espaço e a história a narrativa do tempo" (MOREIRA, 2009, 21 p.).

\section{A sistematização da geografia (Humboudt e Ritter)}

Alexander Von Humbuldt (1769-1859) e Karl Rtitter (1779-1859) são contemporâneos, e sistematizam a geografia enquanto ciência, ou seja, a transformam em um saber orientado pela teoria e pela explicação metódica, incorporando as contribuições de Kant, porém seguem caminhos diferentes (MOREIRA, 2009), marcam a chamada geografia moderna.

Ritter é geógrafo de formação, é responsável por levar a geografia para um novo patamar epistemológico, levando-a "[...] a transpor a fase taxonômica e descritiva [...] para a da representação moderna, centrada no conceito e na explicação" (MOREIRA, 2010, 15p.).

Transforma a corografia no que chama de método comparativo. Objetivando encontrar a "significação na organização corográfica da superfície da terrestre, que ele identifica sob o nome de individualidade regional dos recortes do espaço" (MOREIRA, 2010, 15p.), compara as paisagens duas a duas retirando os traços comuns e as singularidades de cada uma (MOREIRA, 2009).

Humbuldt considera a esfera das plantas como mediação "[...] entre a esfera inorgânica das rochas e dos solos e a esfera humana da sociedade [...]" (MOREIRA, 2009, 23 p.), partindo da classificação e corografia das paisagens:

"Cada paisagem botânica é relacionada para baixo com a base inorgânica e para cima com a intervenção da vida com o homem, para daí, a partir da comparação dos recortes de paisagens segundo o método de Ritter, inferir sua visão holística da Terra" (MOREIRA, 2010, 15p.).

Moreira, 2010, afirma que Humboldt atraiu mais a atenção de seus contemporâneos, mas ambos são esquecidos por quase cinquenta anos, devido a uma fase fragmentadora que se segue. 


\section{O positivismo e a fragmentação da ciência}

Segunda Revolução Industrial "[...] fragmenta o trabalho, o pensamento e a sociabilidade exaustivamente, a começar pela fragmentação do conhecimento numa diversidade infinita de formas de ciência" (MOREIRA, 2010, 16p.).

“O positivismo é a expressão maior dessa sociedade técnica" (MOREIRA, 2010, 16p.), neste momento a natureza é vista sob um prisma físico e matemático, as demais ciências buscam uma modelização pautadas na física. A geografia é a última ciência a fazer isso, começando com inorgânico e em seguida atingindo a esfera humana, mas a modelização matemática desta última não dará muito certo. Por esta razão na virada dos séculos XIX e XX, surgem as geografias física e humana.

\section{Ratzel}

Friedrich Ratzel (1844-1904) desenvolveu sua teoria em dois trabalhos principais, "Antrpogeografia" e "Geografia Política", o chão era a base das relação entre estado e sociedade, esta base era chamada por ele de "espaço vital", ele afirma que os homens constantemente buscam ampliar este espaço vital, isso acontece de duas formas "[...] conseguindo incorporar ares de seu território ainda não ocupadas ou ocupando mais intensivamente o que já se apossaram" (MOREIRA, 2009, 27p.).

\section{Reclus}

Eliseé Reclus (1830 - 1905), foi aluno de Ritter, é geógrafo de formação anarquista, antecipa a geografia de caráter social e político. Viveu boa parte de sua vida no exílio, boa parte de sua produção foi feita nesta condição, como meio de sobrevivência. Escreveu roteiros de orientação turística, que chamaram a atenção da editora Hachete pela qualidade dos textos, esta editora publica então seus trabalhos científicos, mas pede para que eles não transpareçam seu posicionamento anarquista. É após, romper com a editora Hachete e publica seu mais importante trabalho "O homem e a Terra", (MOREIRA, 2009), obra em seis volumes, publicada entre 1905 e 1908, neste trabalho ele dissolve a dicotomia tempo/espaço, depois de ter isso com a dicotomia homem/natureza, em "A terra" e, com a geografia regional/geografia sistemática em "Nova geografia universal" (Moreira, 2010). 
La Blache

Paul Vidal de La Blache, discípulo de Ritter, cria a versão acadêmica da geografia francesa, foi o primeiro professor regular de geografia em uma universidade na frança. Seu trabalho intitulado "Quadros da geografia da frança", lança as bases da geografia regional francesa, e foi escrito a pedido do historiador Ernest Lavesse, “[...] está nessa obra a base do conceito de região que vai batizar a Geografia vidaliana como uma geografia regional e que municiará seus discípulos da teoria e do método - o método regional [...]" (MOREIRA , 2010, 27 p.).

Sua publicação póstuma "Princípios de geografia humana" que deu origem a geografia da civilização, desta obra La Blache apenas deixou em texto definitivo o capítulo introdutório, o restante da obra foi sistematizado por E. de Martone, a partir de manuscritos (MOREIRA, 2009 e 2010).

\section{Brunhes}

Moreira, 2010, diz que Jean Brunhes, pode ser considerado o introdutor do pensamento dialético na geografia. Seu conceito chave eram os "fatos visuais", este conceito valoriza o visual e o empírico, para ela o valor central da reflexão geográfica estava na paisagem e em seu viés cartográfico.

Apesar de não ser muito reconhecido por isso antecipou "[...] muitos dos descursos sobre o esgotamento dos recursos hídricos [...]" (MOREIRA, 2010, 29p.).

\section{Sauer}

Carl Sauer (1889 - 1975), mistura o foco regional da geografia francesa e o "enfoque morfolófico da paisagem" da geografia alemão, para criar "A morfologia da paisagem", ensaio de 1925. Depois sofre influencia da antropologia e "[...] desloca seu discurso no sentido da cultura e da sua arrumação regional" (MOREIRA, 2009, 33p.), dando origem as regiões culturais (MOREIRA, 2009).

\section{Hartshorne}

Richard Hartshorne (1899 - 1992), leva “[...] a geografia norte-americana a recentrar seu foco na diferenciação de áreas do conceito hettneriano" (MOREIRA, 2009, 33p.) 


\section{RESULTADOS}

A geografia é um saber antigo, mas sua sistematização como ciência se deu de forma tardia, iniciou-se com Kant na Alemanha, onde Houboldt e Ritter dão continuidade a esta sistematização, apesar da importância destes pensadores pra a consolidação da geografia enquanto ciência, sua obras são deixadas de lado nas década seguintes (MOREIRA, 2010).

La Blache, o primeiro professor regular de geografia em uma universidade francesa foi discípulo de Ritter, que também teve como aluno Reclus. Assim percebe-se que houve a influencia de pensadores alemães na geografia produzida na França.

No Brasil, de forma geral a geografia sofreu forte influência da matriz francesa, tanto que geógrafos franceses estiveram aqui para fundar os cursos universitários da USP e da UDF, respectivamente em São Paulo e no Rio de Janeiro, entre eles estavam Pierre Monbeing, Pierre Deffontaines e e Francis Ruelan, que trazem "[...] a Geografia de Vidal de La Blache, Brunhe e alguma coisa de Reclus, a que o tempo acrescenta Sorre, George e Tricart, além do norte americano Hartshorne" (MOREIRA, 2010, 23p.), que está ligado a formação do IBGE - Instituto Brasileiro de Geografia e Estatística.

Desta maneira, percebe-se que a geografia produzida em um determinada lugar sofre influencia dos pensadores de outros, além disso há discordância de pensamento de autores que pertencem a um mesmo país, por isso, entre outros motivos, Moreira, 2010, afirma que a idea de "escolas do pensamento geográfico", que coloca dentro de um mesmo conjunto autores contemporâneos de mesma nacionalidade apresenta incoerências, pra este autor, a forma mais clara de estudar o pensamento geográfico está nas matrizes, que considera as ideias e as obras de cada pensador. Porém, o próprio Moreira, já havia utilizado o conceito de "escolas do pensamento geográfico" em outras obras, esta mudança de visão demonstra a mutabilidade das ciências e a importância de uma revisão constante de conceitos e conhecimentos que podem ser considerados acabados.

\section{CONCLUSÃO}

A geografia é um saber rico e muito antigo, usado por vários povos de forma cotidiana, mas isso não impediu que a sistematização destes vastos saberes na forma de uma ciência acabasse acontecendo de forma tardia.

Como é natural de todo conhecimento construído pelo homem, pois ele é elaborado por pessoas, que evidentemente tem seus pensamentos influenciados pelo contexto no qual estão 
inseridas, a geografia sofreu muita influência do contexto histórico, político, social, cultural em que foi produzida.

Estes fatos foram relevantes para a construção da geografia enquanto ciência, a amplitude dos saberes reunidos dentro desta ciência; sua consolidação tardia; a influência do positivismo que fragmentou a geografia em vários saberes setorizados; e influência da física e dos modelos matemáticos que introduziram uma frustrada modelização na geografia, levou os geógrafos a uma busca por identidade, que perdura até os dias atuais, pois há primeira vista tudo parece ser estudado pela geografia.

Mas ao analisarmos o legado dos geógrafos a pluralidade é perceptível, mas esta ideia equivocada de que tudo pode ser estudado pela geografia se torna equivocada.

\section{REFERÊNCIAS}

MOREIRA, Ruy. O Pensamento Geográfico Brasileiro: as matrizes clássicas originárias v.1. 2 ed. São Paulo: Contexto, 2010. 190p.

O que é Geografia. 2 ed. São Paulo: Brasiliense, 2009. 94p.

SPOSITO, Eliseu Savério. Geografia e Filosofia: contribuições para o ensino do pensamento geográfico. São Paulo: Unesp, 2004, 218p. 